\title{
ORGANIZAÇÃO DO TRABALHO: ESTUDO DE CASO DE UMA EMPRESA DE MATERIAIS PARA CONSTRUÇÃO NO MUNICÍPIO DE BARRA DO BUGRES/MT
}

\author{
Thiago Fernandes ${ }^{1}$ \\ Valdemir Lino Nascimento ${ }^{2}$
}

\begin{abstract}
RESUMO
A questão da produtividade é hoje, mais do que nunca, tema de discussões que se desenvolvem desde os recintos acadêmicos até o interior das empresas. O material aqui apresentado é o resultado de uma pesquisa sobre características do processo da organização do trabalho nos sistemas de produção de empresas industriais, cujo enfoque, voltado para o aspecto organizacional propriamente dito. $\mathrm{O}$ objetivo deste artigo é propiciar alguns subsídios para esse debate, abordando a implementação de alguns modelos e técnicas organizacionais para melhor desenvolvimento das atividades que a empresa já executa. Referencia-se nos diálogos e sobre a base teórica de autores, que procuram demonstrar como o uso de novas técnicas pode trazer benefícios e vantagens competitivas para o atual cenário da empresa. Esse trabalho justifica-se frente ao desenvolvimento e as implantações de novas tecnologias ao cenário da construção civil. Além disso, o mesmo faz um relato do atual panorama das atividades desenvolvidas, comparando-as com a base teórica utilizada, diagnosticando possíveis falhas na empresa. A partir dessa percepção, conclui-se que foram elencadas mudanças, atribuindo assim novas maneiras de realizar a divisão do trabalho de forma adequada, conforme o referencial utilizado.
\end{abstract}

Palavras-Chave: Organização do trabalho. Departamentalização. Modelos Organizacionais.

\section{Introdução}

Devido ao grande crescimento do setor de construção civil na região de Barra do Bugres, a 170 km da capital, empresas deste segmento estão se adaptando as novas exigências do mercado para acompanhar o presente desenvolvimento. O sucesso da organização, além da adaptação a mudanças, inovação, padrão de qualidade e produtividade, também depende da cooperação e satisfação dos funcionários no ambiente de trabalho.

Nesta fase inicial se apresenta a teoria dos sistemas para facilitar a visão e a compreensão do modelo de administração aplicado pela empresa. A Organização será examinada não como empresa, mas como a ação de organizar uma empresa, tal como proposto como função administrativa. Será feita a abordagem da função “organizar" com destaque para a divisão de trabalho, de definir a estrutura organizacional de uma empresa.

\footnotetext{
${ }^{1}$ Bacharel em Engenharia de Produção Agroindustrial - Universidade do Estado de Mato Grosso - UNEMAT. E.mail: thyago_2fernandes@hotmail.com.

${ }^{2}$ Acadêmico do curso de Ciências Contábeis - Universidade do Estado de Mato Grosso - UNEMAT. E.mail: lino.1202@hotmail.com 
O objetivo principal do trabalho é alertar a importância da informação para a tomada de decisão a partir de fontes internas e externas. Em seguida a empresa é mostrada como um sistema aberto, juntamente com a necessidade da visão sistêmica no desenvolvimento dos sistemas, voltado para a gerência e posteriormente serão demonstrados os cuidados necessários para a implementação dos sistemas aplicados a organização. Por fim, neste trabalho serão apresentadas revisões teóricas para embasamento da analise do estudo realizado, e relatar as visitas feitas in loco.

\section{Referencial Teórico}

$\mathrm{Na}$ construção teórica, o presente trabalho aborda as noções e concepções sobre departamentalização, descentralização e realização de uma análise específica da distribuição do trabalho na empresa observada. A partir de uma leitura e pesquisa bibliográfica realizada nas obras de Djalma de Pinho Rebouças de Oliveira e Antonio Cury, possibilitou-se uma análise detalhada sobre as noções especificadas no parágrafo anterior.

Para (OLIVEIRA, 2002), departamentalização é a divisão ou agrupamento que leva em consideração um critério de igualdade das características das atividades e correspondentes recursos (humanos, financeiros, materiais e equipamentos) em determinada unidade organizacional.

Depois de realizado esse agrupamento, é necessário que seja feita a representação gráfica da nova estrutura organizacional montada a partir de departamentos, ou seja, a construção do organograma. Especificamente a departamentalização utilizada para organização da empresa pesquisada e observada será a "departamentalização funcional", que se fundamenta na concepção de que as atividades são agrupadas de acordo com as funções exercidas dentro da empresa.

Através dessa ideia, é possível determinar as vantagens que uma empresa poder obter a jusante conforme a empregabilidade correta desse modelo, como por exemplo, uma maior expectativa e segurança no contato direto dentro da organização entre os funcionários, tanto através das tarefas como no relacionamento entre os mesmos, fixação do individuo a sua atividade, ou seja, orienta o funcionário a se habituar e desenvolver a sua função especifica, concentrando a sua competência de maneira eficaz.

É de importância relevante evidenciar também as desvantagens desse modelo, visto que o funcionário, neste tipo de modelo pode ser considerado chefe funcional e com isso 
achar que sua função é a mais importante na empresa, ocasionando abuso de poder e desentendimentos internos, mas isso só ocorrerá se os objetivos da organização não forem colocados em primeiro lugar.

Outro requisito analisado na empresa foi à centralização do poder na alta administração. Contudo, o objetivo a ser alcançado é da descentralização, ou seja, a menor concentração do poder de decisão na alta administração da empresa, fazendo com que as decisões sejam tomadas de forma mais distribuída pelos diversos níveis hierárquicos existente na organização.

A centralização de poder pode acarretar outra dificuldade para o bom andamento de uma organização, sendo ela a má distribuição de funções e carga de trabalho, ou seja, alguns funcionários realizando muitas funções e muitos funcionários realizando poucas atividades dentro da empresa, desta maneira podem levar uma pessoa de maneira inconsciente a ter ociosidade.

Segundo (OLIVEIRA, 2002), existem três objetivos básicos para o enquadramento da distribuição da carga de trabalho no ambiente de trabalho. São eles: tem-se a necessidade de distribuir de forma igualitária as tarefas a serem realizadas pela empresa. Em seguida, redistribuir de forma criteriosa e racional as tarefas já efetuadas pela empresa. E por último, servir como instrumento de análise da real situação e futuras mudanças necessárias a jusante.

Para que ocorra uma melhor distribuição da carga de trabalho é de extrema necessidade que sejam estabelecidas algumas fases. $\mathrm{O}$ primeiro passo se restringe a listagem de tarefas individuais, que ocorre através de entrevistas com os funcionários com o objetivo de conhecer as tarefas que os mesmos executam durante sua carga horária de trabalho, levando em consideração seu tempo de execução.

A segunda fase é feita pela listagem das atividades da unidade organizacional, ou seja, logo após da identificação das tarefas de cada funcionário realiza individualmente, deve-se agrupá-las em atividades, conforme o nível da sua importância. E por último, acontece a elaboração do quadro de distribuição do trabalho de forma igualitária e segundo a especificação da sua função.

A elaboração do quadro mencionado acima é de grande importância, pois o mesmo é uma valiosa ferramenta de análise que possibilita verificar a organização e os métodos de funcionamento utilizados em cada departamento analisado. Outra importância dessa elaboração é averiguar se ocorre equilíbrio no volume de trabalho realizado pelos 
funcionários e também diagnosticar se existem tarefas que são efetuadas por vários executores ou si os funcionários estão as executando de forma dispersa.

A partir de outra visão sistêmica, a relação da distribuição do trabalho dentro de uma organização tem como finalidade identificar a carga de trabalho de cada unidade organizacional, visando diagnosticar eventuais tempos mortos, identificar as tarefas de maior importância e aquelas que exigem maior tempo de manipulação por parte de cada funcionário de maneira individual. A partir dessa nova concepção, deve-se desenvolver um equilíbrio entre a distribuição de todas as tarefas efetuadas dentro departamento analisado (CURY, A. 2000).

É importante enfatizar a hierarquia dentro de uma empresa, que segundo Fayol é a série de "chefes" que vai da autoridade superior aos agentes inferiores. Sendo assim, a hierarquia corresponde a uma forma de organização social que tem como característica: graduação rígida da autoridade e definição exata das atribuições de cada extrato. Outras características para identificar os níveis hierárquicos dentro de uma organização baseiam-se nas tarefas, nas funções, na posição e não no cargo que o indivíduo exerce, na qualificação das pessoas e na dignidade que é concedida ao trabalhador.

Dessa forma, quando a situação exige os administradores de empresas nos níveis mais elevados podem delegar parte de sua carga de trabalho aos administradores nos níveis mais inferiores, o que resulta numa redução da carga de trabalho do mesmo (CURY, A. cap. 5).

Após a análise desses importantes aspectos que podem ajudar no encaminhamento de uma boa administração, é relevante acrescentar a delegação de tarefas como sendo outra perspectiva importante a ser aderida dentro de uma empresa, que é a transferência de determinado nível de autoridade de um chefe para seu subordinado, criando a correspondente responsabilidade pela execução da tarefa delegada. A qual permite coordenar trabalhos mais complexos, com maior produtividade da equipe de trabalho, proporcionando maior segurança para a empresa, dentre outros aspectos em que a mesma busca.

Diante disso, no mesmo processo deve ser considerada a capacidade real e percebida do chefe e de seus subordinados, o fator dominante da decisão da delegação, tudo isso leva a determinação da melhor maneira pra se conseguir o máximo de desempenho total da empresa, ou seja, deve haver um planejamento do chefe para que isso ocorra (OLIVEIRA, cap. 7).

Por fim, o estudo da distribuição do trabalho tem como finalidade avaliar a distribuição do trabalho das atividades entre os diversos órgãos, e dentro destes quais as tarefas individuais de cada empregado, sobre tudo, com o reconhecimento das necessidades 
da organização pela alta administração, de acordo com Cury. Assim, facilita para o analista de sistema, instituir a organização e métodos necessários para aperfeiçoar os melhores resultados que a empresa procura alcançar, por meio da adequada implementação dos modelos administrativos envolvidos.

\section{Metodologia}

Esta pesquisa consiste em um estudo de caso desenvolvido em uma empresa do setor de construção civil, localizada na cidade de Barra do Bugres. Considerando-se que o objetivo da presente pesquisa é investigar como funciona e como são empregados os modelos referentes à Organização do Trabalho na empresa escolhida.

A única técnica que permitiria identificar os indicadores mais adequados é o estudo de caso, trata-se de uma abordagem metodológica de investigação especialmente adequada quando procuramos compreender, explorar ou descrever acontecimentos e contextos complexos, nos quais estão simultaneamente envolvidos diversos fatores, que se baseia em realizar um diagnóstico confiável e propor sugestões à empresa para a melhoria da sua estrutura organizacional (Yin 1994). A etapa inicial do estudo teve como objetivo elaborar um questionário para analise da situação real da empresa. A etapa subsequente ao questionário foi à visita in loco, pra levantamento de dados para possíveis melhorias no ambiente de trabalho. Esta fase teve como foco principal elencar os modelos de organização do trabalho previamente selecionados como os principais para implementação na empresa, com base no referencial teórico pesquisado.

A partir da identificação dos pontos a serem melhorados pode-se realizar um planejamento das ações a serem realizadas para que fossem propostas atividades que auxiliem no aumento de produtividade e na maximização de lucros a partir de uma visão sistêmica.

\section{Resultados da Pesquisa}

\subsection{A Empresa}

O estudo de caso foi desenvolvido em uma loja de materiais para construção civil, a empresa atua neste setor a vinte e três anos, revende seus produtos tanto para consumidores de pequeno porte, ou seja, aqueles que fazem compras esporádicas para reformas ou pequenos reparos, como também fornece materiais para grandes empresas da região, e realiza convênios 
com uma instituição financeira para construção de casas, esta parceria realiza financiamentos de materiais para construção utilizados nas obras.

A empresa já atua no mercado há muitos anos, como já foi mencionado anteriormente, possui funcionários que ali trabalham desde a sua fundação. Está localizada no município de Barra do Bugres, Estado de Mato Grosso. Conta com uma força de trabalho de 22 funcionários. Sua estrutura organizacional é centralizada nos seus dois sócios, que fazem parte do Conselho Administrativo, sendo que um deles exerce a função de presidente da empresa.

\subsection{Diagnóstico da Empresa}

Conforme dados levantados e coletados junto à empresa. Pode-se perceber que os níveis hierárquicos da loja não são bem estabelecidos, possuindo assim setores em que não há monitoramento por parte de um supervisor de departamento, e sim a figura do presidente da empresa que delega funções em todos os níveis hierárquicos.

Com a centralização de poder na alta administração a distribuição da carga de trabalho na empresa esta sendo realizada de forma desigual e desorientada, visto que todas as decisões devem ser compartilhadas com a alta administração, quando que o mais indicado é que os funcionários encarregados de cada setor detivessem mais poder de tomada de decisão. A descentralização nessa empresa deve ser desenvolvida para aguçar o desenvolvimento gerencial de seus diretores que se encontram especificamente, na média e baixa administração, e também para proporcionar uma maior elevação da participação, motivação e comprometimento por parte dos funcionários.

Importante também salientar a criação e desenvolvimento de departamentos mais fundamentados, ou seja, a distribuição de funcionários de acordo com suas especificidades, visando aglomerar em cada departamento aqueles funcionários que detém mais conhecimento naquela área específica, onde o correto seria profissionalizar os mesmos ou contratar pessoas com qualificação em determinada área, por exemplo, contador para setor financeiro, administradores para coordenar cada departamento dentre outros.

Ouro fator vantajoso e realizar reuniões num espaço de tempo mais curto, não apenas de maneira isolada, ou seja, em cada departamento, mas também um representante de cada segmento da empresa deveria compor essa reunião de forma que as decisões sejam tomadas 
de maneira a visar o progresso de todos os níveis da organização, pois um nível depende do outro para que a organização como um todo possa crescer.

$\mathrm{Na}$ empresa foi verificado que somente o departamento de vendas possui reuniões periódicas a cada quarenta e cinco dias, para estabelecer as metas a serem alcançadas, mostrar uma melhor maneira de abordagem dos clientes entre outras funções específicas dos vendedores. Neste caso, como dito anteriormente os funcionários de departamentos diferentes não são interligados de nenhuma outra forma.

Verificou-se então a necessidade da descentralização de poder, devido às decisões serem tomadas apenas por um dos proprietários, sobrecarregando-o e muitas vezes dificultando a visibilidade de constatar com rapidez os problemas ou até mesmo prevenir que ocorra alguma possível falha.

Como fundamentado na revisão teórica, a distribuição da carga de trabalho no ambiente de trabalho não está ocorrendo de forma a permitir o desenvolvimento do funcionário em sua função, tendo a necessidade de distribuir de forma justa as tarefas, redistribuir de forma criteriosa e racional (segundo as características e atribuições de cada funcionário) e por último, analisar os pontos que necessitam ser mudados. Uma maneira de materializar essa concepção de divisão de tarefas é a elaboração do quadro de distribuição do trabalho de forma igualitária e segundo a especificação da sua função, segundo mencionado no referencial teórico.

A divisão do trabalho de forma igualitária é uma das maneiras de evitar que seja atribuída várias funções ao mesmo funcionário, independente do setor a qual foi designado, como por exemplo, foi diagnosticado no setor de RH que os funcionários além de operar para a loja, também prestam serviços para fazendas, e isso ocorre devido às mesmas serem dos proprietários da loja de materiais para construção.

No fluxograma apresentado a abaixo para implementação na empresa, tem-se a utilização da delegação de tarefas como sendo um fator importante a ser aderido dentro de uma empresa, que é a transferência de determinado nível de autoridade de um chefe para seu subordinado, criando uma responsabilidade pela execução da tarefa delegada.

A qual permite que cada diretor possa coordenar trabalhos em que o mesmo lida diariamente e tem mais contato do que a figura do presidente, interferindo em todos os departamentos ao mesmo tempo, não possibilitando com essa atitude que o mesmo se atente aos detalhes, essa percepção detalhista pode fazer uma extrema diferença, ocasionando maior 
Organização do trabalho: estudo de caso de uma empresa de materiais para construção no Município de Barra do Bugres/MT

Thiago Fernandes; Valdemir Lino Nascimento

produtividade da equipe de trabalho, proporcionando maior segurança para a empresa, no que diz respeito à apresentação de possíveis mudanças ocasionadas de forma mais fundamentada.

Para melhor compreensão e analise do sistema organizacional da empresa, temos a seguir o modelo do fluxograma atual, e também o modelo de fluxograma que seria a melhor opção para a organização, através da formulação de diretorias, o que possibilitaria maior organização da empresa.

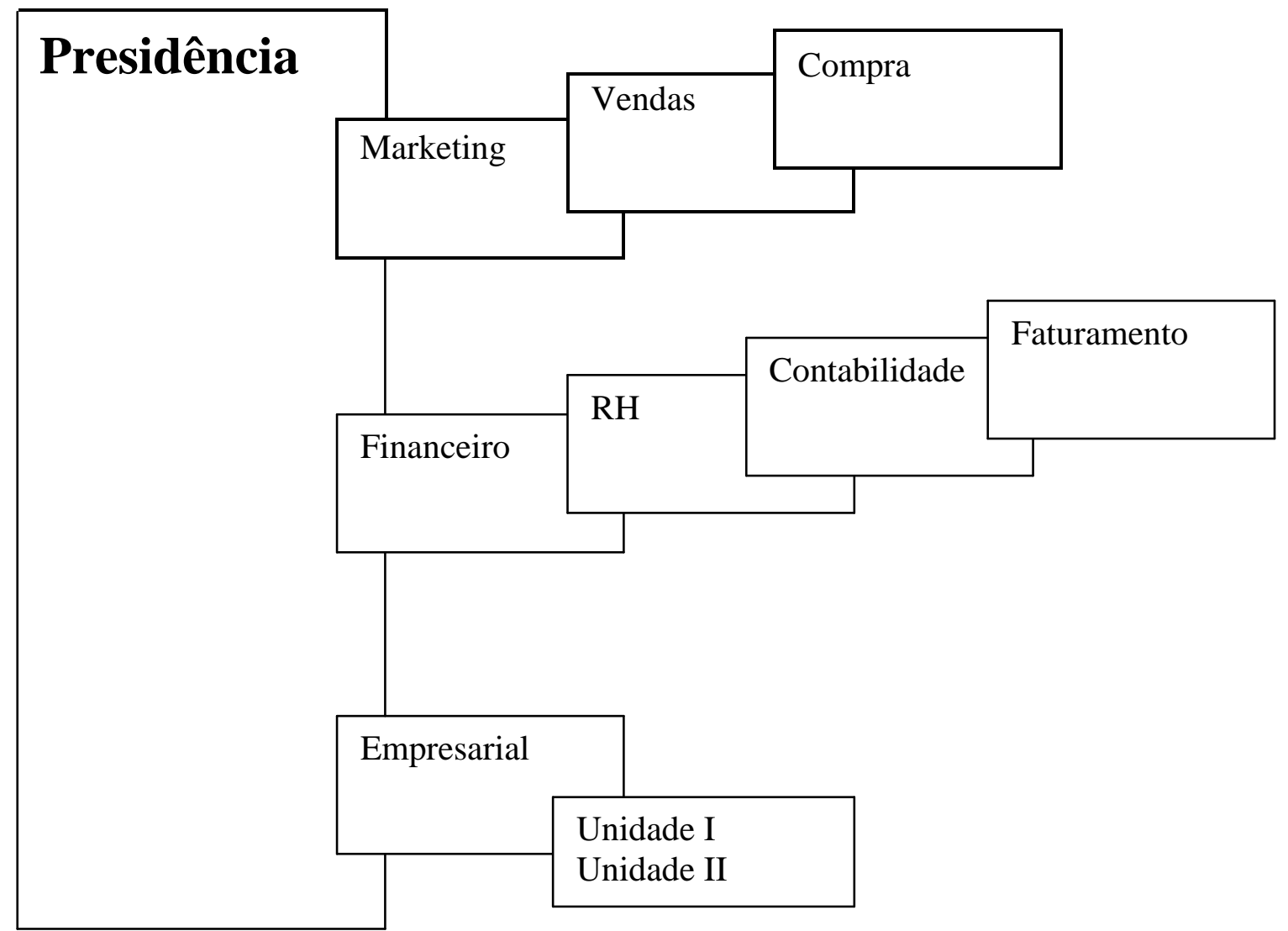

Figura 01: Fluxograma atual da empresa em analise.

Fonte: Elaborado pelo autor, 2012.

Fluxograma que seria de melhor aplicação para a organização, através da formação funcional de diretorias.

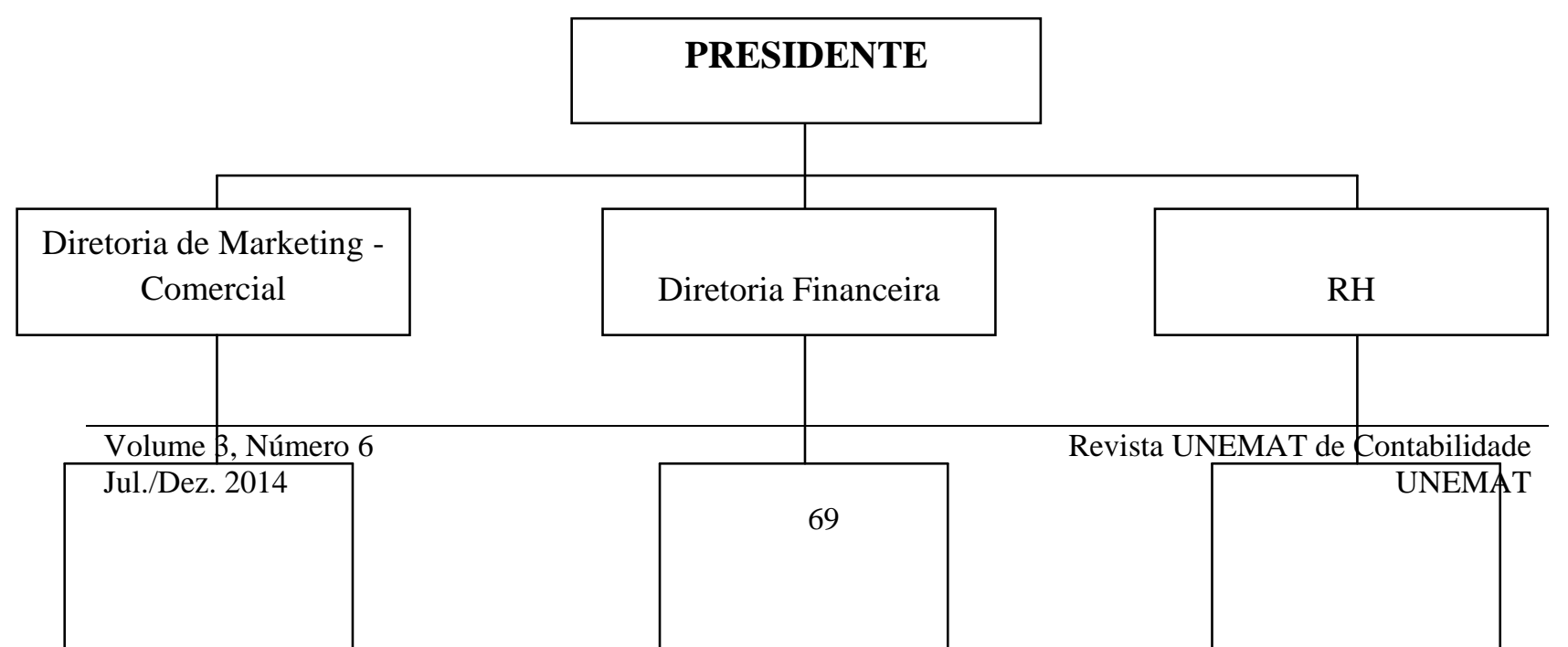


Figura 02: Fluxograma proposto.

Fonte: Elaborado pelo autor, 2012.

São notórias as vantagens em departamentalização por funções conforme feito no segundo fluxograma, esse método agrupa pessoas especializadas sob uma chefia (diretor de cada departamento); garante o máximo de utilização das habilidades técnicas de cada pessoa; orienta a mesma para atividade específica e o sistema de comunicação por rede, permite que as informações e o funcionamento da estrutura aconteçam de forma integrada e eficaz.

Deve-se levar em consideração como a forma estrutural pode atender às necessidades de comunicação da empresa, como enfatizado no decorrer do trabalho, os aspectos básicos do sistema de responsabilidade em uma empresa funcional são: departamentalização e linha de assessoria.

Estes aspectos estão relacionados à prestação de contas de quem adquiriu a responsabilidade, seguindo uma linha de comando estabelecida pela empresa, e dando o direito de quem está à frente do departamento fazer melhorias, tomar decisões e dar ordens conforme a autoridade que lhe foi designada sempre visando o desenvolvimento da organização.

No fluxograma apresentado para implementação na empresa, tem-se a utilização da delegação de tarefas como sendo um fator importante a ser aderido dentro de uma empresa, que é a transferência de determinado nível de autoridade de um chefe para seu subordinado, criando uma responsabilidade pela execução da tarefa delegada.

A qual permite que cada diretor possa coordenar trabalhos em que o mesmo lida diariamente e tem mais contato do que a figura do presidente, visto no primeiro fluxograma, interferindo em todos os departamentos ao mesmo tempo, não possibilitando com essa atitude que o mesmo se atente aos detalhes, essa percepção detalhista pode fazer uma extrema 
diferença, ocasionando maior produtividade da equipe de trabalho, proporcionando maior segurança para a empresa, no que diz respeito à apresentação de possíveis mudanças ocasionadas de forma mais fundamentada.

\section{Conclusão}

Nesta pesquisa pode-se concluir que através do referencial teórico analisado teve-se a oportunidade de obter conhecimento suficiente para identificar os problemas existentes na administração da empresa como um todo, e propor possíveis soluções e melhorias que visam contribuir para um melhor desenvolvimento e feedback dos departamentos através modelos administrativos citados e explanados.

\section{Referencias Bibliográficas}

CURY, Antônio. Organização e métodos: uma visão holística. $7^{\circ}$ ed. São Paulo: Atlas, 2000.

OLIVEIRA, Djalma de Pinto Rebouças . Sistemas, organização \& métodos: uma abordagem gerencial. $13^{\circ}$ ed. São Paulo: Atlas, 2002.

STONER, James A. F., FREEMAN, R. Edward. Administração. $5^{\circ}$ ed. Rio de Janeiro:

PHB, 1992 YIN, Robert K. Estudo de caso: planejamento e métodos. 3.ed. Porto Alegre: Bookman, 1994. 